\title{
STUDI TINGKAT PENGETAHUAN PEMANFAATAN LAYANAN PITC (PROVIDER INITIATED TES TING AND COUNSELING) PADA PASIEN BERESIKO Human Immunodeficiency Virus (HIV) DI PUSKESMAS PANAMBUNGAN KOTA MAKASSAR
}

\author{
Nurlia Naim \\ Jurusan Analis Kesehatan Poltekkes Kemenkes Makassar
}

Koresponden: nurlianaim0416@gmail.com

\begin{abstract}
ABSTRAK
Penelitian ini berlatarbelakang semakin tingginya angka kesakitan dan kematian yang disebabkan oleh HIV/AIDS saat ini, serta diperlukan peranan klinik bimbingan dan penyuluhan serta uji secara sukarela untuk membantu setiap individu mendapatkan akses pelayanan, informasi, edukasi, dan dukungan psikososial khususnya terhadap individu yang beresiko maupun yang telah terinfeksi oleh HIV/AIDS. Permasalahannya adalah sejauh manakah tingkat pengetahuan tentang pemanfaatan layanan PITC terhadap masyarakat khususnya bagi individu yang rentan dan beresiko terhadap HIV/AIDS. Adapun tujuan penelitian ini yaitu untuk mengetahui tingkat pengetahuan pemanfaatan. Jenis penelitian yang dilakukan menggunakan pendekatan observasional (pengamatan) dan merupakan jenis penelitian deskriptif. Populasi penelitian ini adalah semua pasien konseling yang berkunjung kelaboratorium PITC. Sampel adalah semua dari jumlah dan karakteristik yang dimiliki oleh populasi, yaitu sebanyak 20 orang pasien. Dari hasil penelitian ini ditarik kesimpulan dengan jumlah responden sebanyak 20 orang dengan tingkat pengetahuan pemanfaatan layanan PITC sebanyak 2 responden (10\%) yang berpengetahuan kurang baik dan 18 responden (90\%) yang berpengetahuan baik.
\end{abstract}

Kata Kunci: Pengetahuan, penularan, pemanfaatan

\section{PENDAHULUAN}

\section{Epidemi}

Immunodeficiency

(HIV)/Acquired Immune Deficiency

Syndrome (AIDS) telah melanda seluruh dunia. Penyakit ini menyebar dengan cepat tanpa mengenal batas negara dan pada semua lapisan penduduk. Hawari (2006) menyebutkan bahwa masalah HIV/AIDS sudah menjadi global effectdengan kecepatan penyebaran yang sangat pesat. World Health Organitation (WHO) atau badan kesehatan dunia menyebutkan penyakit ini sebagai wabah paling mematikan sepanjang sejarah dan mengantisipasi hal ini dengan membentuk organisasi khusus penanggulangan HIV/AIDS (Joint United Nations Programme on HIV/AIDS) dan menetapkan tanggal 1 Desember sebagai hari AIDS se dunia.

Kasus pertama dari HIV/AIDS ini ditemukan di San Fransisco pada seorang gay tahun 1981. Menurut United Nations 
Programme on HIV/AIDS (UNAIDS) atau Badan PBB(Perserikatan Bangsa-Bangsa) yang menanggulangi masalah AIDS di duniapada tahun 2013, di seluruh dunia ada 35 juta orang hidup dengan HIV yang meliputi 16 juta perempuan dan 32 juta anak berusia $<15$ tahun. Jumlah infeksi baru HIV pada tahun 2013 sebesar 2,1 juta yang terdiri dari 1,9 juta dewasa dan 240.000 anak berusia $<15$ tahun. Jumlah kematian akibat AIDS sebanyak 1,5 juta yang terdiri dari 1,3 juta dewasa dan 190.000 anak berusia <15 tahun. (Infodatin Kemenkes RI, 2014)

Kasus AIDS pertama di Indonesia terjadi di Bali pada bulan April tahun 1987. Penderitanya adalah seorang wisatawan Belanda yang meninggal di Rumah Sakit Umum Pusat(RSUP) Sanglah akibat infeksi sekuler pada paru-parunya (Muninjaya, 1998).

Di Indonesia jumlah kasus

HIV dari sejak pertama kali dilaporkan pada tahun 1987 sampai tahun 2014 triwulan 3 cenderung meningkat. Sedangkan kasus AIDS cenderung menurun. Jumlah kumulatif penderita HIV dari tahun 1987 sampai September 2014 sebanyak 150.296 orang, sedangkan kumulatif kasus AIDS 10 tahun pertama masih tergolong rendah. Akhir tahun 1997, jumlah kasus AIDS kumulatif hanya 153 kasus dan HIV positif 486 orang. Pada akhir abad ke 20 terlihat kenaikan kasus AIDS yang sangat berarti dan di beberapa daerah pada sub populasi tertentu, angka prevalen sebanyak 55.799 orang. (Ditjen PP \& PL Kemenkes RI, 2014)

Berdasarkan data nasional penularan HIV, factor resiko mengalami perubahan dalam 5 tahun terakhir, dan infeksi HIV dominan terjadi pada kaum heteroseksual $(61,5 \%)$, kelompok "lain-lain" $(17,1 \%)$, pengguna napza suntik (penasun) $(15,2 \%)$ dan kelompok lelaki berhubungan seks dengan lelaki (LSL) $\quad(2,4 \%)$. (Ditjen PP\&PL Kemekes RI, 2014)

Pada Tahun 2013 Kementrian Kesehatan RI meluncurkan inisiatif penggunaan Antiretroviral (ARV) atau dikenal dengan Stategic Use of $A R V$ (SUFA) dimana salah satu jenis kegiatannya yaitu Test Konseling Inisiatif Petugas (TIPK) atau Provider Initiated Testing And Counseling (PITC). (www.depkes.go.id, 2014)

Lima kabupaten/kota di Provinsi Sulawesi Selatan yakni Makassar, Parepare, Pinrang, Sidrap dan Jeneponto merupakan daerah rawan penularan HIV/AIDS (KOMPAS.com).

Laporan pemeriksaan HIV (layanan PITC) Puskesmas Panambungan pada tahun 2015 sebanyak 198 orang dimana jumlah pemeriksaan perbulan yaitu sebanyak 10 - 20 orang, di dominasi oleh pasien ibu hamil dan pasien berobat Tuberculosis (TB) dan beberapa orang yang mempunyai factor resiko tinggi.

Dinas Kesehatan Provinsi Sulawesi selatan pada tahun 2014 melaporkan Sulawesi Selatan termasuk dalam 10 peringkat teratas dengan jumlah kasus HIV dan AIDS tertinggi, sebanyak 8423 orang, HIV sebanyak 5474 dan AIDS sebesar 2949. Dimana penularan tertinggi melalui penggunaan narkoba suntik (penasun) sebesar 30,3 \% diikuti dengan penularan lewat hubungan 
heteroseksual tidak aman $(36,5 \%)$ lewat hubungan homoseksual tidak aman $(4,6 \%)$ dan lain lain 28,6 \%.

Kota Makassar termasuk Kabupaten/Kota dengan kasus HIV tertinggi di Sulawesi Selatan dengan jumlah kasus sebanyak 6428 (82\%) dengan peningkatan jumlah kasus rata-rata 25 - 30 kasus baru setiap tahunnya. (dinas kesehatan Provinsi Selawesi Selatan, 2014).

Pada tahun 2013 Dinas Kesehatan Kota Makassar telah membuka layanan PITC di semua Puskesmas (46 puskesmas) di kota Makassar dan terlebih dahulu membuka klinik Voluntary Counseling Test (VCT)yang terdapat pada RSUP Wahidin Sudirohusodo Makassar, Rumah Sakit Umum Daerah(RSUD) Labuang Baji Makassar, Rumah Sakit Umum (RSU) Polri Bhayangkara, RSUD Dadi Makassar, Pusat Kesehatan Masyarakat (Puskesmas) Ujungpandang Baru, Puskesmas Kassi-Kassi, Puskesmas Makassau, P puskesmas Jongaya, dan Puskesmas Batua Makassar.

Mencermati data tersebut diatas yang erat kaitannya dengan belum efisiennya pengetahuan tentang pemanfaatan layanan PITC bagi pasien beresiko HIV, maka penulis telah melakukan penelitian berupa studi tingkat pengetahuan pemanfaatan layanan PITC bagi pasien beresiko HIV di Puskesmas Panambungan Kota Makasssar.

METODE

\section{Jenis dan Desain Penelitian, Lokasi dan waktu penelitian}

Jenis penelitian yang dilakukan menggunakan pendekatan observasional (pengamatan) yang merupakan jenis penelitian deskriptif. Lokasi penelitian dilaksanakan di Puskesmas Panambungan Kota Makassar tanggal bulan April - Juni 2017.

\section{Populasi, Sampel dan Teknik Pengambilan Sampel}

Populasi penelitian ini adalah semua pasien konseling yang berkunjung ke laboratorium PITC. Sampel adalah semua dari jumlah dan karakteristik yang dimiliki oleh populasi, yaitu sebanyak 20 orang pasien. Teknik pengambilan sampel menggunakan Accidental Sampling yaitu meneliti pasien yang berkunjung langsung ke laboratorium PITC. Kriteria Objektif ditentukan dengan merujuk pada skala likert. Setiap variabel pengetahuan ini memiliki 5 pertanyaan yang masing-masing pertanyaan akan mendapatkan jawaban yaitu:

a. Jika responden memilih opsi Ya, diberi skor (2)

b. Jika responden memilih opsi Tidak, diberi skor (1)

Skor tertinggi jawaban responden adalah $(\mathrm{X})$ :

Jumlah pertanyaan $\mathrm{X}$ skor jawaban tertinggi 5 x $3=15(100 \%)$

Skor terendah jawaban responden adalah (Y):

Jumlah pertanyaan $\mathrm{X}$ skor jawaban terendah 5 x $1=5(20 \%)$

\section{Pengetahuan pasien adalah:}

Bagus: persentase total jawaban responden $\geq 60 \%$

Tidak Bagus: Jika persentase total jawaban responden $<60 \%$

Maka ukuran skor total tiap variabel

$$
\text { : } \quad \frac{60}{100} \times 15=9
$$

Kriteria Objektif variabel :

Bagus : Jika skor jawaban responden $\geq 9$ 
Tidak Bagus : Jika skor jawaban responden $<9$

\section{Pengumpulan, Pengolahan dan} analisa data penelitian

Data yang dikumpulkan terdiri dari data primer dan data sekunder. Data primer adalah data yang diperoleh dari responden (sampel) langsung melalui wawancara berpedoman pada kuesioner yang telah disusun mencakup variabel independen yaitu pengetahuan pasien serta variabel dependen yaitu pemanfaatan PITC. Sedangkan data sekunder merupakan data yang diperoleh laporan-laporan di laboratorium PITC Puskesmas Panambungan Kota Makassar. Analisa Data dilakukan secara deskriptif untuk mendapatkan gambaran umum dengan cara mendeskripsikan tiap variabel serta untuk menjawab tujuan penelitian yaitu melihat distribusi frekuensinya dengan menggunakan program SPSS 16.0

\section{Karakteristik Responden}

\section{Jenis Kelamin}

Tabel 1.

Karakteristik responden berdasarkan jenis kelamin

\begin{tabular}{ccc}
\hline Jenis & Frekuensi & Persen $(\boldsymbol{\%})$ \\
Kelamin & & 35 \\
Laki-laki & 7 & 65 \\
Perempuan & 13 & 100. \\
Total & 20 &
\end{tabular}

Sumber : Data Primer 2017

Pada tabel 1. dapat dilihat dari 20 responden pada penelitian ini lakiperempuan sebanyak 13 orang ( 65 $\%)$.

\begin{abstract}
HASIL
dilakukan di Laboratorium Panambungan pada tanggal 25 April s/d 17 Juni 2017. Instrumen yang digunakan berupa kuesioner yang dibagikan kepada responden atau klien yang berkunjung ke Laboratorium PITC Puskesmas Panambungan, dengan jumlah sampel sebanyak 20 orang. Jenis penelitian yang dilakukan menggunakan pendekatan observasional (pengamatan) yang merupakan jenis penelitian deskriptif. Analisa data dilakukan untuk mendapatkan gambaran umum dengan cara mendeskripsikan tiap variabel yang digunakan dalam penelitian yaitu melihat distribusi frekuensinya dengan menggunakan program SPSS 11.5.Adapun variabel yang dimaksud dalam analisa adalah sebagai berikut :
\end{abstract} laki sebanyak 7 orang (35\%) dan

Tabel 2.

Karakteristik responden berdasarkan umur

\begin{tabular}{ccc}
\hline Umur & Frekuensi & Persen (\%) \\
\hline$<04$ tahun & 0 & 0 \\
\hline
\end{tabular}




\begin{tabular}{ccc}
\hline $5-14$ & 0 & 0 \\
Tahun & & \\
$15-19$ & 2 & 10 \\
Tahun & & \\
$20-24$ & 5 & 25 \\
Tahun & & 55 \\
-49 Tahun & 11 & 10 \\
$\geq 50$ Tahun & 2 & 100 \\
\hline Jumah & 20 &
\end{tabular}

Pada tabel 2. dapat dilihat dari 9 responden pada penelitian ini yang terbanyak adalah responden dengan umur 15 - 19 tahun sebanyak 6 orang (10\%), responden dengan umur 20 - 24 sebanyak 5 orang (25\%), responden umur $25-49$ Tahun sebanyak 11 orang (55\%), dan responden $>50$ tahun sebanyak 2 orang $(10 \%)$.

\section{Pendidikan Terakhir}

Tabel 3.

Karakteristik responden berdasarkan pendidikan terakhir

\begin{tabular}{ccc}
\hline $\begin{array}{c}\text { Pendidikan } \\
\text { Terakhir }\end{array}$ & Frekuensi & $\begin{array}{c}\text { Persen } \\
(\%)\end{array}$ \\
\hline SD & 2 & 10 \\
SLTP & 5 & 25 \\
SLTA & 10 & 50 \\
Perguruan & 3 & 15 \\
Tinggi & 20 & 100 \\
Total & Sumber: Data Primer 2017
\end{tabular}

Pada tabel 3., dapat dilihat dari 20 responden terdapat 3 orang $(15 \%)$ yang berpendidikan terakhir di perguruan tinggi, sebanyak 10 orang (50\%) yang berpendidikan terakhir
SLTA, sebanyak 5 orang (25\%) yang berpendidikan terakhir SLTP dan sebanyak 2 orang (10\%) yang berpendidikan terkahir SD.

\section{Status Pernikahan}

Tabel 4.

Karakteristik responden berdasarkan status pernikahan

\begin{tabular}{ccc}
\hline $\begin{array}{c}\text { Status } \\
\text { Pernikahan }\end{array}$ & Frekuensi & $\begin{array}{c}\text { Persen } \\
(\%)\end{array}$ \\
\hline Belum Menikah & 2 & 10 \\
Menikah & 16 & 80 \\
Janda & 1 & 5 \\
Duda & 1 & 5 \\
Total & 20 & 100. \\
\hline
\end{tabular}

Sumber: Data Primer 2017 
Pada tabel 4. dapat dilihat dari 20 responden terdapat 2 orang $(10 \%)$ yang belum menikah, 16 orang (80\%) yang telah menikah, 1 orang
(5\%) yang berstatus janda dan 1 orang $(5 \%)$ yang bersatus duda.

\section{Variabel Yang Diteliti}

\section{Pengetahuan}

Tabel 5.

Karakteristik pengetahuan responden terhadap penyakit HIV/AIDS

Pengetahuan Frekuensi Persen

\begin{tabular}{ccc} 
& & $(\mathbf{\%})$ \\
\hline Kurang Baik & 2 & 10 \\
Baik & 18 & 90 \\
Total & 20 & 100. \\
\hline Sumber: Data & Primer & 2017
\end{tabular}

Pada tabel 5. dapat dilihat dari 20 responden pada penelitian ini yang terendah adalah responden yang berpengetahuan kurang baik sebanyak 2 orang ( $10 \%)$ sedangkan responden yang berpengetahuan baik sebanyak 18 orang (90\%).

\section{Penularan}

Tabel 6.

Karakteristik Pengetahuan Responden terhadap Penularan HIV/AIDS

\begin{tabular}{ccc}
\hline Penularan & Frekuensi & Persen (\%) \\
\hline Tidak & 1 & 5 \\
Ya & 19 & 95 \\
Total & 20 & 100.0 \\
\hline \multicolumn{3}{c}{ Sumber: } \\
Data Primer 2017
\end{tabular}

Pada tabel 6. dapat dilihat dari 20 responden pada penelitian ini, adalah responden yang menjawab Ya

\section{Pemanfaatan}

Tabel 7. Karakteristik pengetahuan responden terhadap pemanfaatan klinik PITC

\begin{tabular}{ccc}
\hline Manfaat & Frekuensi & Persen $(\%)$ \\
\hline Tidak & 16 & 80 \\
Ya & 4 & 20 \\
Total & 20 & 100.0 \\
\hline
\end{tabular}

Sumber: Data Primer 2017

Pada tabel 7. dapat dilihat dari 20 responden pada penelitian ini sebanyak 19 orang ( $95 \%)$ dan responden yang menjawab Tidak sebanyak 1 orang $(5 \%)$.

responden yang menjawab Ya sebanyak 2 orang ( $20 \%$ ) sedangkan 
responden yang menjawab Tidak sebanyak 16 orang $(80 \%)$.

\section{KESIMPULAN}

Dari hasil penelitian tentang "Studi Tingkat Pengetahuan Pemanfaataan layanan PITC (Provider Initiated Testing and Counseling)pada pasien beresiko HIV di Puskesmas Panambungan Kota Makassar dengan jumlah responden sebanyak 20 orang dengan tingkat pengetahuan pemanfaatan layanan PITC sebanyak 2 responden (10\%) yang berpengetahuan kurang baik dan 18 responden (90\%) yang berpengetahuan baik.

\section{SARAN}

Dari hasil kesimpulan diatas dapat disarankan:

1. Kepada pihak Puskesmas Panambungan untuk lebih meningkatkan penyuluhan tentang pemanfaatan layanan PITC pada umumnya dan pengetahuan dan penularan HIV/AIDS pada khususnya.

2. Kepada Kementerian Kesehatan agar lebih gencar lagi dalam upaya meningkatkan penyuluhan tentang dampak dari penularan HIV/AIDS serta pemanfaatan layanan PITC.

3. Kepada pihak Dinas Kesehatan untuk melengkapi tenaga dengan konselor yang mempunyai latar belakang tertentu seperti pemuka agama yang bisa memberikan pencerahan spritual kepada para klien atau pasien yang berkunjung ke layanan PITC khususnya dan masyarakat pada umumnya

\section{DAFTAR PUSTAKA}

Aggleton, P.; Rivers, K; Warwick, I., and Whitty, G., 1994. Learning About AIDS: Scientific and Sosial Issues, Second Edition, United Stated of America: Churchill Livingstone.

Modul Bagi Peserta, Dijen PP \& PL Kemenkes RI, Jakarta

Hawari, D., 2006. Global Effect HIV/AIDS Dimensi Psikoreligi, Jakarta:Balai Penerbit FKUI.

Muninjaya, 1998. AIDS di Indonesia, Masalah dan Kebijakan Penanggulangannya, Jakarta: EGC.

Nasir, Riskiyani, 2014, Laporan penelitian Integrasi Upaya Penanggulangan HIV \& AIDS Ke Dalam Sistem Kesehatan di Provinsi Sulawesi Selatan, FKM

Universitas Hasanuddin dan UGM

\begin{tabular}{llr} 
Nursalam, & \multicolumn{1}{c}{$2007 . \quad$ Asuhan } \\
& Keperawatan Pada \\
& Pasien Terinfeksi \\
& HIV/AIDS.Penerbit \\
& Salemba. \\
Zein F, & 2013, Testing dan \\
& Counseling (PITC) \\
& Dalam Program \\
& Penanggulangan \\
& HIV/AIDS, \\
& www.miumipusat, \\
& Jakarta
\end{tabular}

Zein, U., 2006. 100 Pertanyaan Seputar HIV/AIDS yang Perlu AndaKetahui, Medan: USU Press 